\title{
Moda sustentável no contexto da hipermodernidade
}

\section{Sustainable fashion in the context of hypermodernity}

NISHIMURA, Maicon Douglas Livramento

Universidade Federal de Santa Catarina -UFSC I mn.mura@outlook.com

SCHULTE, Neide Köhler

Universidade do Estado de Santa Catarina - UDESC I neideschulte@gmail.com

GONTIJO, Leila Amaral

Universidade Federal de Santa Catarina - UFSC I leila.gontijo@ufsc.br

\begin{abstract}
Resumo
Ao considerar a plasticidade da moda às mudanças da sociedade e a reconfiguração do sistema que está à procura de práticas mais sustentáveis, objetivouse desenvolver um projeto de coleção de moda embasado nos princípios da moda sustentável no contexto da hipermodernidade. Assim, foi observado que as reflexões do período dialogam com as emergências de pautas socioambientais, mas, sob a sistemática do Slow Fashion, diversas dificuldades são apontadas, principalmente em relação à matériaprima.
\end{abstract}

Palavras-chave: Moda. Coleção. Sustentabilidade. Hipermodernidade.

\section{Abstract}

Considering the adaptability of fashion to the changes in society and the reconfiguration of the production system, that is in search of more sustainable practices, the objective of this paper is to develop a fashion collection based on the principles of sustainable fashion in the context of the hypermodernity. Thus, we observed that the current reflections on the topic are aligned with the emergence of the socio-environmental agenda, but under the perspective of Slow Fashion - several difficulties arise, mainly in relation to the use of raw materials.

Key-words: Fashion. Collection. Sustainability. Hypermodernity. 


\section{INTRODUC̣ÃO}

A atual expansão tecnológica remodelou a sociedade e fez surgir uma nova geração intitulada " $Y$ " ou "milleniuns". Os precursores dessa geração vivenciaram uma transição que os fizeram adaptar-se com muita agilidade. Os meios de pesquisa, a comunicação e o envio de dados passaram a ocorrer por meio digital. Nesse caminho de informatização, empresas privadas, setores públicos e as famílias mudaram suas configurações. Nas organizações, as interações humanas diminuíram para a otimização de processos sob o pretexto de diminuição de erro e aumento da segurança informacional. Os lares abriram mão do diálogo familiar para o registro de todas as ações cotidianas nas redes sociais, em tempo real e alcance global.

A rede criada revalorizou conceitos impregnados na sociedade. No passado, bastava a verbalização para firmar contrato entre famílias, hoje, a confiança é contestada. Por exemplo, as relações estabelecidas na internet são impessoais ou multifacetadas, as pessoas não precisam ser sinceras e podem adquirir múltiplas personalidades sem haver a verificação da identidade do usuário. Além de toda a mudança ocorrida nas relações, essa geração vive em dualidade com o sistema capitalista no qual está inserida. O consumo permaneceu, entretanto, a grande quantidade de carga informacional faz com que os indivíduos questionem tudo, inclusive o modo de consumir.

Talvez os questionamentos atuais não sejam tão filosóficos e teóricos, na realidade possuem uma forte carga empírica e, certamente, são mais rasos em conteúdo devido à velocidade com que a informação é gerada e consumida. Porém, o conhecimento está cada vez mais acessível, seja na linguagem ou no domínio. Assim, o sistema, dogmas religiosos, relações de poder são questionados e a democracia é elucidada para defender a opinião coletiva. Então, nesse contexto de possibilidades para a construção de novos sentidos, a moda estabelece um papel significador.

Dentro de uma realidade de consumo, a produção em escala industrial permanece para atender uma população mundial que cresce exponencialmente. Contudo, os consumidores demonstram desagrado com marcas que não vão ao encontro daquilo que é importante para si, como a valorização do ser humano, dos seus direitos de expressão, assistências básicas à saúde e educação. Podem-se verificar atitudes em relação a esses valores nos manifestos que procuram o esclarecimento por parte de empresas que fazem uso de mão-deobra escrava, apresentam condições de trabalho precárias e realizam o uso e descarte inadequado de matéria-prima no setor de vestuário.

No sentido de questionar as práticas agressivas de produção oriundas da realidade hipermoderna, principalmente na área de moda, sistemas e modelos de negócios sustentáveis exploram soluções para atender o volume 
de demanda de consumo com uma abordagem consciente que preencha requisitos socioambientais. Baseado no ritmo acelerado de informação, remodelamento das relações e novos valores, propôs-se desenvolver uma coleção de moda embasada em princípios de moda sustentável no contexto da hipermodernidade.

\section{HIPERMODERNIDADE}

A temporalidade histórica é marcada por momentos que se consagram e representam todo um período. O surgimento da escrita para a Pré-História, as quedas dos Impérios Romanos do Ocidente e do Oriente, que sinalizam a Idade Antiga e a Idade Média, e a Revolução Francesa que inicia a Idade Moderna, são exemplos dessa delimitação temporal.

O que vem a seguir causa estranhamento sob a visão do que havia se estabelecido. Até a Idade Moderna, os períodos acompanhavam longos anos de homogeneidade política, cultural e social até um momento de gradual mudança que resulta em uma nova época. Todavia, a Pós-Modernidade caracterizouse por muitas transformações, principalmente na esfera social, que fez com que Lipovetsky (2004) questionasse o ritmo da sociedade em "Os Tempos Hipermodernos".

A indagação acerca da Pós-Modernidade surge com o pressuposto de que a sociedade está ligada, sobretudo, ao gozo do presente, diferentemente da Antiguidade que estava relacionada ao passado e, da Modernidade, que vislumbrava um futuro (LIPOVETSKY, 2004). Inclusive, o autor define que a Pós-Modernidade findou e deu espaço para a Hipermodernidade, uma vez que o primeiro período valoriza o presente e o segundo desvencilha-se da tradição e teme as expectativas da ciência, ao questionar o passado e o futuro, meio a controvérsias e constante inquietude.

Para Lipovetsky (2004) a complexidade do presente está relacionada ao fato da sociedade viver contradições, de experienciar a liberdade de expressão sugerida pela democracia e, ao mesmo tempo, o autocontrole de um sistema público pautado na autovalorização. Isto é, busca-se viver intensamente sem ultrapassar os limites dos outros.

Todavia, o presente não elimina o passado. Pode-se analisar o futuro sob a perspectiva do presente. De acordo com o autor, o indivíduo mesmo que egocêntrico, advém de um contexto histórico e filtra elementos provenientes da tradição a fim de trazer uma nova significação para as relações. Esclarece ainda que o indivíduo hipermoderno não é centrado na posteridade, mas está atento na forma de que o por vir pode afetar aquilo que se vive no momento, culminando em muita angústia. 
Na mesma direção, Bauman (2001) retrata o tempo atual com a expressão "liquidez", em que o indivíduo possui caráter mutável, adaptativo e evolutivo para vivenciar uma liberdade desejada, mas que enfrenta certa dificuldade para lidar com as consequências da mesma como, por exemplo, a validação de suas decisões e atitudes pela sociedade.

Por mais que a sistemática se altere rapidamente, mesmo com a exclusão de dogmas e desconstrução de conceitos, algumas coisas não se demonstram mutáveis. Valores como amor, afetividade e sinceridade se mantém sólidos em um cenário de grande variabilidade (LIPOVETSKY, 2004).

Entretanto, um fator que interage e leva à luz da reflexão do conceito de hipermoderno é o tempo. Tudo acontece em um ritmo acelerado em que corrobora para que se tenha um comportamento intenso e ansioso, não mais prazeroso. Para compensar, o consumo surge como meio de preencher o vazio paradoxal do tempo. Contudo, o indivíduo que consome não age mais de forma desenfreada, porque desenvolveu um olhar apurado, apesar de superficial (LIPOVETSKY, 2004).

Baseado nisso, Gonçalves (2011, p. 333) afirma que,

Vários sinais fazem pensar que entramos na era do hiperconsumismo e hipernarcisismo. Estamos numa sociedade que massifica, padroniza e, ao mesmo tempo, cria seres autônomos e ambíguos, estimula os prazeres e produz comportamentos angustiados e esquizofrênicos divididos entre uma cultura do excesso e o elogio da moderação. Em contrapartida, o medo de tornar-se obsoleto faz com que fiquemos obcecados por informação, pelo novo, inédito, consumamos nossa própria existência prolongando incessantemente nosso imaginário com pseudonecessidades, fenômeno que extrapola as categorias de classes sociais.

$\mathrm{E}$, intimamente ligada ao consumo, há a mídia. Meio que exerceu forte influência massificadora para o consumo na modernidade. $E$, do mesmo modo na hipermodernidade, empenha-se em comunicar a abundância de opções para a multiplicidade de personas que se estabelecem (LIPOVETSKY, 2004).

Segundo Bauman (2001), a amplitude de possibilidades permitida pela modernidade líquida, faz com que se dissolva alguns poderes e influências, mas para que se exerça o controle, os líderes utilizam da sedução para atingir seus objetivos. Dessa forma, o estímulo do consumo por um influenciador transforma o indivíduo influenciado em uma terceira personalidade, isto é, ele deixa de ser quem é, para se tornar algo a partir daquele que o influenciou. 
Esses novos perfis dão lugar para a individualidade que, por sua vez, desloca a atenção exclusiva para a atenção partilhada, em que todos possuem seu momento no tempo e espaço (BAUMAN, 2001). O autor ainda trata de que a sociedade transita, de modo fluido, para preencher vazios que surgem pela mudança social.

\section{MODA SUSTENTÁVEL}

Sob o viés da hipermodernidade, que trabalha a relação do indivíduo com o tempo, de um ponto de vista narcisista e consumista, o setor de vestuário ganha maior proporção pelo fato das sociedades modernas terem na roupa objeto de significação. Assim, é a partir do final do século XIX que o vestuário adquire o espírito efêmero com o advento da alta costura e se estabelece na temporalidade das relações sociais e de poder (LIPOVETSKY, 1991).

Passada essa fase de elaboração conceitual do vestuário no contexto da moda, novos desafios surgem ao passo que a indústria evolui. A história é marcada com o declínio da alta costura, por meio da popularização de suas tendências no prêt-à-porter, com a globalização da produção que eclode no Fast Fashion e, por conseguinte, o surgimento de um sistema que reflete os questionamentos e as controvérsias dos tempos hipermodernos, a moda sustentável.

O sistema Fast Fashion abrange um grande número de negócios em todo o mundo e dita o ritmo da produção industrial. Com o ciclo de moda rápida, os prazos na cadeia produtiva de moda se tornaram mais curtos e o ciclo de vida do produto também, a fim de atender uma demanda apreensiva por novidade (SALCEDO, 2014).

O ciclo de vida do produto se refere à trajetória percorrida pelo produto, desde a extração da matéria-prima até o seu descarte. Salcedo (2014) apresenta o ciclo de vida de uma peça de roupa, que inicia seu processo no campo, com a extração da fibra para posterior construção do tecido, em seguida, tem-se a etapa de criação, com o design e a confecção, que é a etapa de materialização do produto final. As etapas de logística, distribuição e venda também estão inclusas nesse ciclo, assim como o período de uso e o descarte.

Sob o olhar da sustentabilidade, o ciclo de vida do produto é uma importante ferramenta informacional. A partir da trajetória e do histórico do produto, com a avaliação dos processos e do comportamento dos envolvidos em cada fase, pode-se assinalar melhorias e alternativas com o intuito de adequar o produto a uma orientação consciente no aspecto socioambiental. De posse dessa ideia, de analisar o ciclo de vida do produto, é que se sugerem o 
ciclo de vida fechado. Isto é, ao invés de considerar que o produto terá um fim (cradle to grave, berço à cova), propõem o conceito de cradle to cradle (berço ao berço), em que ocorre a reutilização do produto (GWILT, 2014).

A proposta de um ciclo verdadeiramente fechado, em que uma nova vida é dada ao produto, direciona a moda para a prática sustentável. Afinal, a questão da sustentabilidade é uma preocupação que se fortaleceu no século XXI, mas remonta do século passado. De acordo com Schulte (2011, p. 54),

O conceito de sustentabilidade ambiental foi concebido no início da década de 70, na Conferência das Nações Unidas sobre o Meio Ambiente, para sugerir que era possível conseguir o crescimento econômico e a industrialização sem destruir o meio ambiente. O modelo proposto para o desenvolvimento sustentável foi uma tentativa para harmonizar o desenvolvimento humano com os limites da natureza.

A autora afirma que o modelo econômico presente sugere uma relação de parceria entre empresas, meio ambiente e sociedade. Contudo, destaca que para atingir a excelência, é necessário que os envolvidos atuem de maneira preventiva e planejada para a mudança em prol do consumo ético e responsável. Uma forma que as empresas encontraram para empreender soluções na redução de impacto ambiental foi a adoção da Responsabilidade Social Corporativa. Conforme Karkotli (2007), as empresas procuram uma gestão mais transparente e o envolvimento da cadeia produtiva a fim de alinhar os objetivos corporativos a uma proposta sustentável.

As empresas que não aderiram voluntariamente ao estilo de uma sociedade sustentável, sofrem hoje com a pressão social. Segundo Lee (2009), a mais de uma década os grandes veículos de comunicação de moda passaram a trazer para suas pautas a questão do "movimento verde". Igualmente, a autora apresenta que as instituiç̃oes de ensino de moda e os desfiles de moda ao redor do mundo já apoiam e abordam a sustentabilidade desde então.

É importante ressaltar o papel das escolas de moda como formador de novos profissionais. Lee (2009) comenta que o designer, aquele que está a frente do desenvolvimento de produto, tem papel essencial na determinação de uma cadeia sustentável. Isto é, a escolha por processos menos agressivos ao meio ambiente e às pessoas, é decisão do profissional no momento da escolha de materiais e acabamentos.

Nos últimos anos, percebeu-se um alinhamento de estilistas e de marcas para práticas sustentáveis, sejam elas éticas, ambientais, sociais ou econômicas. A seguir estão listados alguns conceitos, reunidos por Chiapetta (2016) para o blog "eCycle", que exemplificam o fenômeno da sustentabilidade na moda. 
a) Eco Chic: conceito que sugere elegância e respeito aos princípios socioambientais;

b) Moda Ética: conceito que considera o impacto socioambiental na cadeia produtiva de moda;

c) Eco Moda (Moda Ecológica ou Moda Verde): conceito que visa a redução de impactos ambientais a partir de um processo produtivo consciente e durante o ciclo de vida do produto;

d) Zero Waste Fashion: conceito que busca uma produção que não gera resíduos e desperdícios;

e) Upcycling: tendência que almeja a redução de lixo pela reutilização de materiais descartados;

f) Slow Fashion: movimento que trabalha com o ideal de uma cadeia produtiva e de um produto de perfil sustentável.

A essa lista de conceitos, adiciona-se mais dois movimentos de repercussão. Um deles é o downcycling que, de acordo com Anicet, Bessa e Broega (2011), visa a reciclagem de materiais a partir da sua transformação e consequente diminuição de qualidade do material. E, ressalta-se o movimento global chamado Fashion Revolution que teve origem no desastre do Rana Plaza, em Bangladesh no ano de 2013, em que 1138 mulheres morreram e outras 2500 ficaram feridas após o desabamento do edifício que apresentava condições precárias (FASHION REVOLUTION, 2017). O movimento tem como fundamentos, a alteração do formato do negócio de moda, a redução do impacto ambiental e social e a mudança da forma de pensar moda, sempre apontando a problemática do consumo como catalisador para o agravamento de todos esses processos (FASHION REVOLUTION, 2017).

Apesar da abundância de conceitos e movimentos, há uma convergência para três caminhos, é o que sugere Nishimura e Gontijo (2017). Os autores apontam que existem movimentos orientados pela ética, que aliam o comércio justo e a ecologia, outros norteados pelo Slow Fashion e aqueles que utilizam práticas de reciclagem. Nesse mesmo sentido de compreender a dinâmica da moda sustentável, Salcedo (2014) categoriza os movimentos existentes. A autora trabalha com três segmentos: sistemas tradicionais como a alta costura; o Fast Fashion; e a Moda Mais Sustentável, sendo que este subdivide-se em Slow Fashion, Moda Ética e Ecomoda.

Todos esses conceitos convergem para uma sociedade que se deparou com o consumo excessivo de matéria-prima e grande acúmulo de resíduos, acompanhado de risco social. Ao passo que se encontram com a inconsistência do sistema atual, o indivíduo hipermoderno, sugerido por Lipovetsky (2004), caminha para uma ressignificação do consumo de vestuário.

Este consumo "sem necessidade" é motivo de crítica à Moda. No entanto, não é o único produto consumido "sem necessidade". Automóveis, mobiliário, entre outros 
produtos também são trocados com frequência sem que apresentem qualquer dano. Apenas porque surgiu um novo produto, mais estético ou com novas funções e novas tecnologias (SCHULTE; LOPES, 2007, p. 4).

Das definições apresentadas anteriormente, o Slow Fashion tem grande representatividade por ser mais do que um conceito ou movimento, ganhou caráter de sistema de moda. O Slow Fashion tem proporções maiores do que a de nicho de mercado em potencial e possui o peso de um sistema por apresentar uma dinâmica que visa fomentar a cadeia produtiva sustentável (NISHIMURA; GONTIJO, 2016).

O termo Slow Fashion foi criado, em 2007, por Kate Fletcher inspirada no Slow Food, proposto por Carlos Petrini na Itália em 1986 (FLETCHER, 2007). Esse movimento tem como objetivo uma alimentação de preparo artesanal com estímulo à comunidade local, desenvolvimento do comércio agrícola, e envolvimento das pessoas de uma região na valorização da comida tradicional. De base das mesmas premissas construiu-se a moda "lenta".

Fletcher (2012) define o Slow Fashion, como uma visão diferenciada para o crescimento embasado no consumo responsável. Com base nesse princípio, procura-se reconfigurar o processo produtivo para valorizar os indivíduos que participam da cadeia de moda, repensar o projeto de produto para que no final agregue-se valores socioambientais, oferecendo um diferencial ao consumidor sem ignorar um custo coerente à proposta (FLETCHER, 2007). Além disso, ressalta-se entre os valores do sistema, a produção lenta orientada para a qualidade e durabilidade da peça, a avaliação do ciclo de vida do produto e a valorização dos seres humanos, da natureza e da cultura (SALCEDO, 2014; FERRONATO; FRANZATO, 2015).

Somados aos conceitos de Slow Fashion de Fletcher (2007) e de Hipermodernidade de Lipovetsky (2004), Calíope (2015, p. 12) defende que,

A moda e a sustentabilidade podem estar relacionadas positivamente a partir do momento em que o consumidor altera sua maneira de consumir moda, priorizando a moda lenta, reduzindo o consumo, adquirindo roupas de qualidade e com estilo atemporal, que poderão ser usadas por muito mais tempo, e, mesmo que o consumidor enjoe elas ainda podem ter uma vida útil.

Dessa forma, a complexa construção antropológica fica simplificada pelas relações sociais ao passo que, coletivamente, os indivíduos buscam alternativas para estabelecer a sua existência de maneira sustentável por meio da ressignificação daquilo que o passado já havia resignado. 


\section{PROCEDIMENTOS METODOLÓGICOS}

O projeto foi realizado em duas etapas. Inicialmente foi realizada uma pesquisa de abordagem qualitativa e de caráter exploratório, embasada em Gil (2010), a fim de obter aprofundamento nos temas hipermodernidade e moda sustentável. Na etapa seguinte, de desenvolvimento de coleção de moda, utilizou-se da metodologia projetual de Löbach (2001), que se divide em quatro fases: preparação, geração, avaliação e realização.

A primeira fase, de preparação, consistiu em analisar o problema de design em seu contexto geral: social, ambiental, mercadológico, funcional, estrutural. No caso desta pesquisa, fez-se o levantamento bibliográfico dos temas hipermodernidade e moda sustentável com o intuito de estabelecer a temática da coleção.

Na fase de geração, em que se exploram alternativas de design, foram propostos conceitos, soluções e ideias para atingir os objetivos do projeto. Elaborou-se os painéis imagético, moodboard, persona, trendboard, cartela de cores e materiais, para a caracterização do usuário e estudar formas, cores e texturas do futuro produto.

A terceira fase consiste em avaliar as alternativas de design sugeridas ao projeto, por meio do desenvolvimento de 100 (cem) croquis de moda. Dessa maneira, foram escolhidas as 20 (vinte) melhores soluções e incrementou-se as ideias para a formulação do conceito de design proposto. Por fim, devido ao custo e o tempo, foram escolhidos apenas três croquis para execução.

Na última fase, de realização, detalhes técnicos foram estudados para o encaminhamento à parte final, de confecção dos produtos. Então, elaborou-se os documentos técnicos necessários o desenvolvimento da coleção de moda.

\section{RESULTADOS}

Com a finalidade de trabalhar a moda sustentável no contexto da hipermodernidade, isto é, desenvolver uma coleção de moda baseada em princípios do Slow Fashion e na conjuntura de uma sociedade acelerada, aliouse formas geométricas da arquitetura urbana para a elaboração de peças contemporâneas, confortáveis e funcionais à produção lenta.

A proposta tem início no acervo de fotografias tiradas por um dos autores em uma viagem ao Japão, do qual foram compiladas as que ilustravam obras arquitetônicas contemporâneas. As imagens foram dispostas de maneira a contar uma história que resume em descoberta, tempo e liberdade, conforme pode ser observado na Figura 1. 
Figura 1 - Fotografias de inspiração.

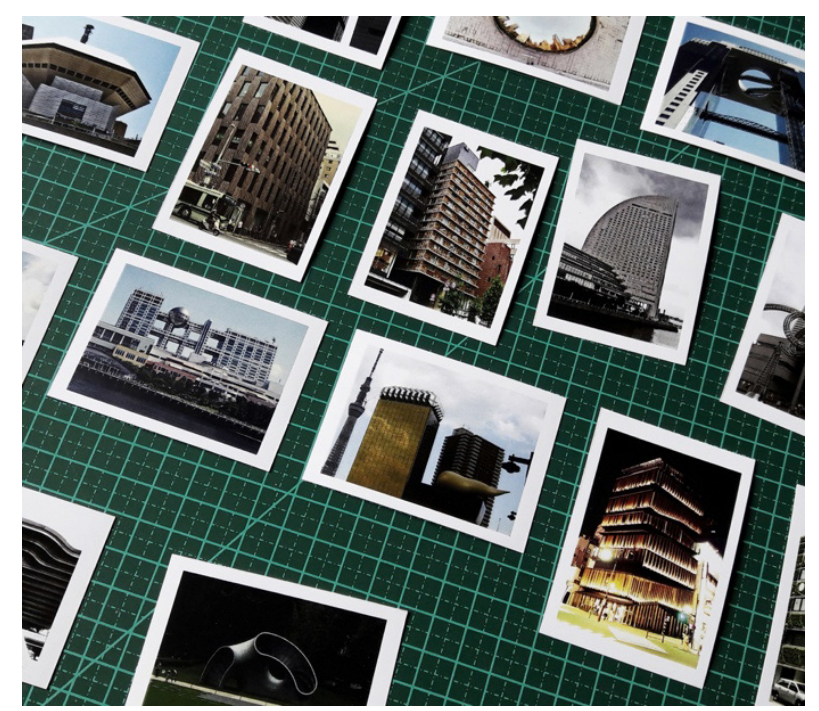

Fonte: Desenvolvido pelos autores (2017).

Formulado o conceito, foram desenvolvidos materiais de aporte para o processo de criação, ou seja, a preparação dos croquis de moda. O primeiro painel criado foi o semântico, que traz as primeiras referências, é a representação imagética do argumento da coleção (TREPTOW, 2007). Definiuse como argumento a Figura 2, que também pode ser traduzido com uma frase de Lipovetsky (2012, p. 3): "Busca-se o tempo todo coisas novas que, ao final, não dão satisfação. Cada vez temos mais coisas, mas o que não significa que estamos mais felizes".

Figura 2 - Painel imagético.

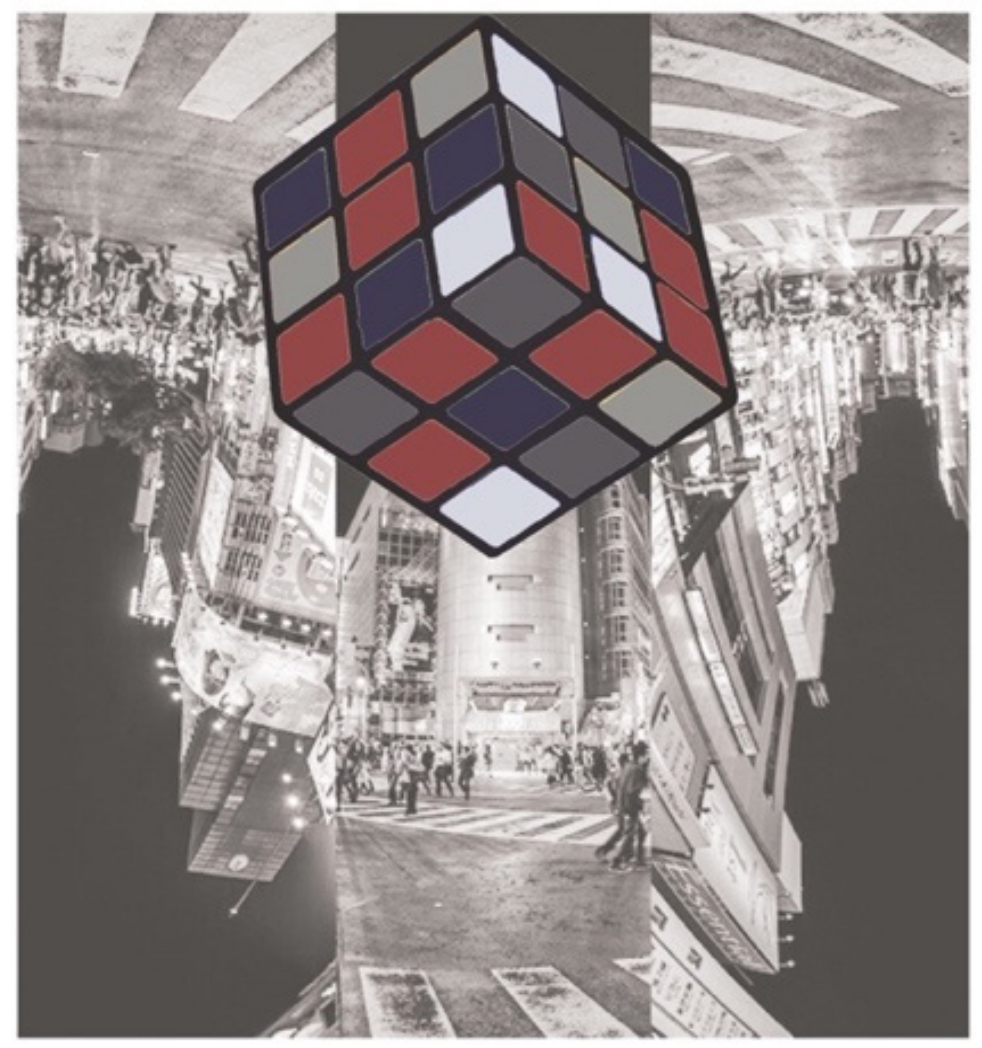

Fonte: Desenvolvido pelos autores (2017). 
Outro painel desenvolvido foi o moodboard (Figura 3), que traduz a atmosfera do projeto por meio de formas, cores e estética. Procurou-se trazer fluidez, suavidade, conforto e possibilidades meio a um universo que transborda informação e demanda escolhas a todo momento.

Figura 3 - Moodboard.

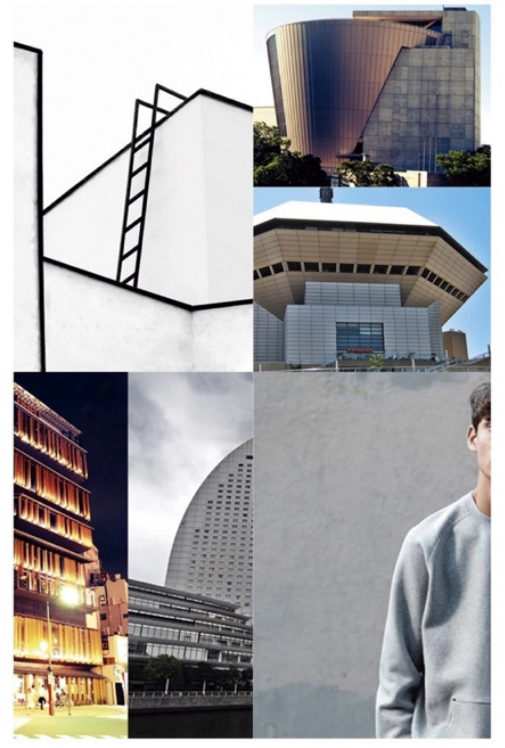

Fonte: Desenvolvido pelos autores (2017).

Com o intuito de definir o público alvo da coleção, delineou-se o painel persona, representado pela Figura 4. 0 indivíduo deste projeto deseja o equilíbrio, físico e emocional. Um homem com idade por volta dos 30 (trinta) anos, independente, que mora sozinho e trabalha com criação/produção/ comunicação. Aprecia gastronomia, cinema, adora viajar e valoriza momentos singulares. Seu cotidiano é balanceado entre trabalho, atividade física e tempo para com os amigos.

Figura 4 - Painel persona.
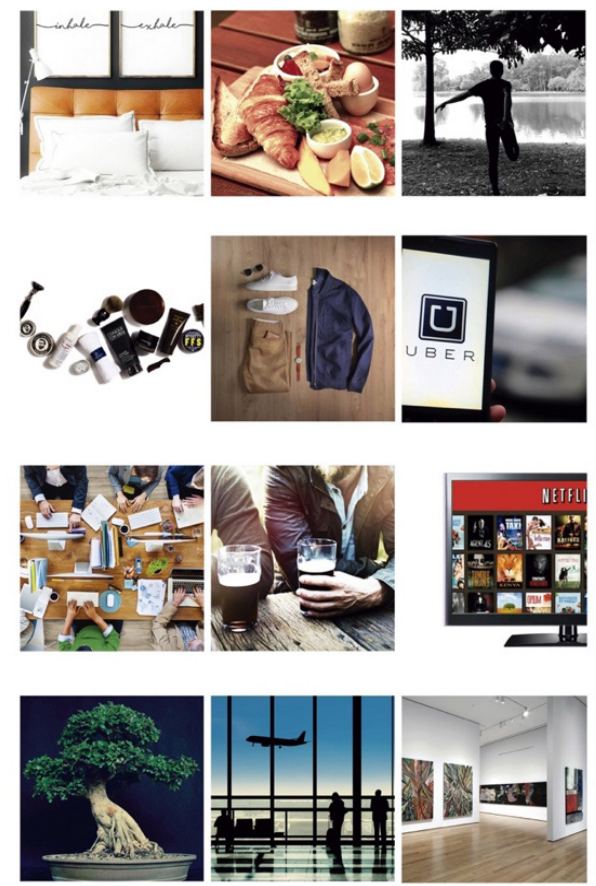

Fonte: Desenvolvido pelos autores (2017). 
Opainel detendências outrendboard (Figura5) reúneinformações coletadas que serão aporte fundamental para nortear o designer no desenvolvimento do projeto com base naquilo que está em voga, conforme Treptow (2007). A coleção é composta por camisetas e regatas com recortes diferenciados, bermudas e shorts que oferecem conforto pela composição e amplitude, calças mais ajustadas ao corpo e com encurtamento no comprimento, jaquetas que exploram as alternativas de detalhes e leggings para agregar estilo e performance ao guarda roupa masculino.

A escolha das matérias-primas ocorre em um momento posterior, mas se destaca que até esta etapa era cogitada a reciclagem de tecidos dentro da proposta do upcycling. Assim, nesse momento de criação de painéis, buscou-se pensar em estratégias que possibilitassem a reutilização de retalhos e restos de tecidos. Então, recortes e peças de modelagem menores foram lançadas como alternativas. E, do mesmo modo, as cores também foram delimitadas pela oferta de variedades no mercado.

Figura 5 - Trendboard.

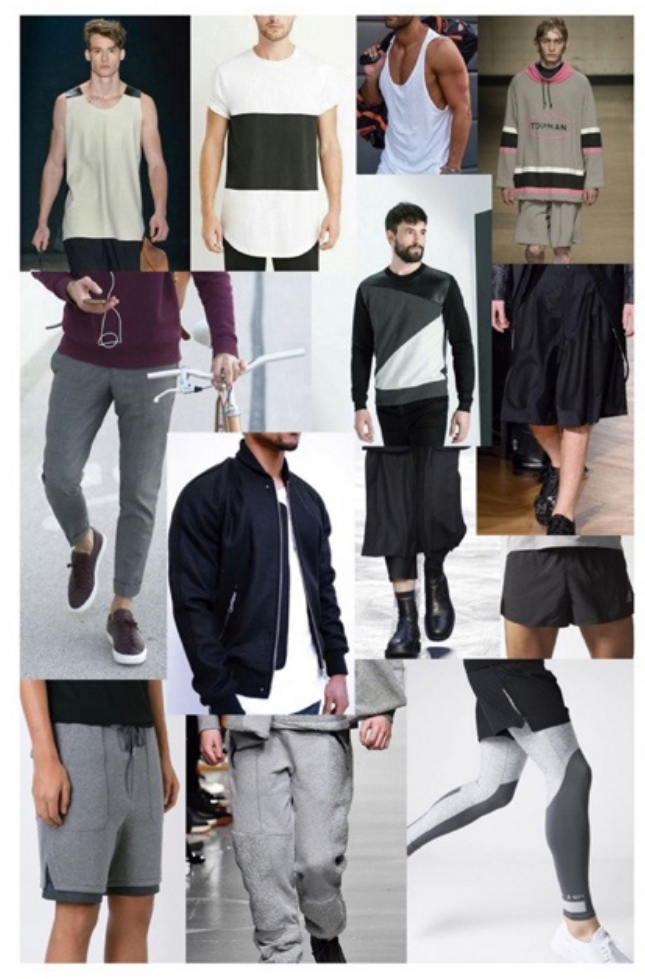

Fonte: Desenvolvido pelos autores (2017).

A cartela de cores, ilustrada pela Figura 6, tem como parâmetro a atmosfera da coleção e, por meio de um layout equilibrado, é exibido em um quadro de fundo branco para transmitir as sensações ao receptor (TREPTOW, 2007). Optou-se por tons sóbrios com inclinação para o escuro. A variedade de cinzas está alinhada ao perfil urbano. O bordô e o azul surgem como complementares, tanto em sua natureza colorística, assim como no cotidiano hipermoderno. O preto vem aliar praticidade para o contexto multitarefa da persona. 
Figura 6 - Cartela de cores.

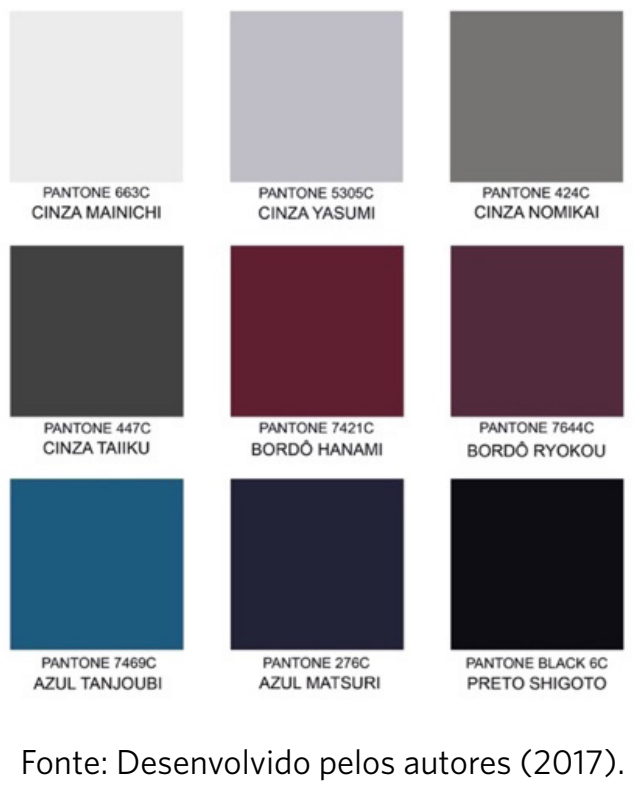

Baseado nos princípios do Slow Fashion, buscou-se materiais no mercado local, que permitissem a durabilidade da peça, com uma ideia de atemporalidade e funcionalidade do uso, além de pensar na possibilidade de um produto viável economicamente dentro de uma visão comercial.

Procurou-se utilizar retalhos e restos de tecidos que um dos autores possuía, mas para o alcance do padrão estético desejado, seria inviável utilizar pequenos pedaços de tecidos distintos. Depois disso, foram pesquisados tecidos alternativos, porém, no mercado local faltaram opções de malhas com certificações ambientais. Avaliou-se a possibilidade de trazer de outras cidades, mas o custo com transporte e o próprio impacto ambiental do combustível seria questionável. Com isso, decidiu-se valorizar empresas familiares locais, de gestão transparente, com produto de alta qualidade e durabilidade que permitirão o uso prolongado das roupas.

Assim, os materiais escolhidos para o projeto foram: moletom, ribana, viscose, lycra e microfibra. A composição é de algodão e materiais sintéticos. O moletom foi escolhido para dar volume e estrutura para bermudas, jaquetas e alguns recortes de camisetas. A ribana dá acabamento para as peças. A viscose, traz fluidez para camisetas e regatas. A lycra permite o movimento e valoriza o contorno. A microfibra oferece caimento e conforto para jaquetas e shorts.

Dos tecidos escolhidos não se pode afirmar que eles não acarretam prejuízos ambientais, afinal, nenhum deles possui selo sustentável ou alguma certificação similar. Todavia, essas escolhas foram feitas com o propósito de compensar por meio do prolongamento do tempo de uso do produto e sua facilidade de manutenção, já que os materiais são comumente utilizados para vestuário de alta performance física. 
Desenvolvidos todos os painéis e escolhidos os materiais, iniciou-se a geração de ideias. A criação das roupas surgiu da abstração geométrica das fotografias citadas anteriormente. A partir do reforço de traçado de algumas linhas dos objetos arquitetônicos, foram transpostas as formas para os croquis de moda pelos recortes na roupa, com o intuito de valorizar, sobretudo, uma modelagem otimizada e confortável.

$\mathrm{Na}$ construção da peça foram desenvolvidas duas etapas, de modelagem e confecção, ambas realizadas por um dos autores. A modelagem foi desenvolvida a partir da Apostila 01, de modelagem infantil e masculina, do Curso de Moda da Universidade W. Utilizou-se as bases da camisa masculina e da calça justa masculina para a interpretação de todas as peças. O resultado final da coleção pode ser observado na figura a seguir.

Define-se a coleção pelo retrato a multiplicidade do indivíduo hipermoderno que tem como inspiração a arquitetura contemporânea japonesa. Conforto e praticidade foram os principais fundamentos, que se apresentam por meio de uma cartela de cores sóbria incorporada a recortes geométricos e uma modelagem ampla.

Figura 7 - Editoriais de moda'.
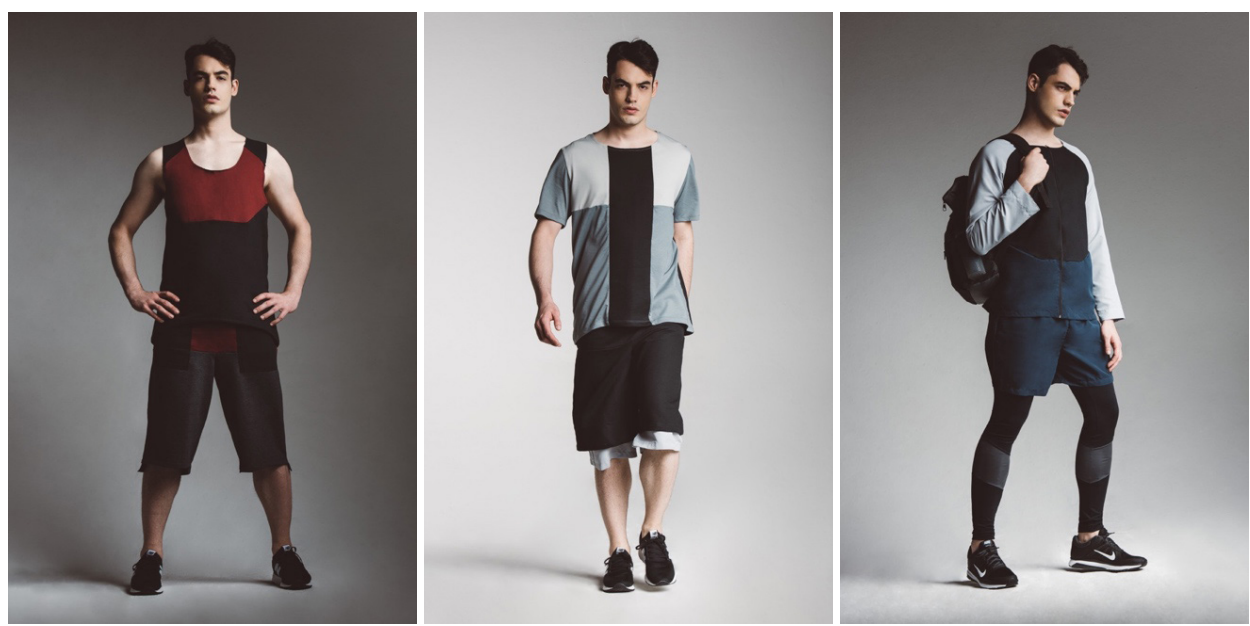

Fonte: Desenvolvido pelos autores (2017).

\section{CONSIDERAC̣ÕES FINAIS}

As práticas sustentáveis na moda, frente às emergências socioambientais atuais, são a concretização dos termos liquidez, de Bauman (2001), e hipermodernidade, de Lipovetsky (2004). A sociedade e as pessoas estão cada vez mais inconstantes, em procura de preencher vazios e evoluindo a cada passo em direção ao futuro. 
Entre os conceitos estudados neste projeto, buscou-se, inicialmente, pensar no desenvolvimento de uma coleção pautada na reciclagem. Contudo, demonstrou-se inviável atingir um padrão estético, mesmo com a adoção de recortes nas roupas. Então, partiu-se para o conceito do Slow Fashion, mais abrangente, no sentido de a roupa possuir significado e valorizar uma produção lenta.

Primou-se por dar uma estética que pudesse se aproximar do conceito de atemporalidade. As cores escolhidas foram mais sóbrias e as formas mais retas. Utilizou-se de formas geométricas e uma modelagem tradicional que permitiu o melhor aproveitamento de tecido. A etapa de corte foi bastante cautelosa, com o intuito de reduzir ao máximo o desperdício de malha.

Diante dessa realidade, foi necessário pensar e investigar alternativas que pudessem atender ao objetivo da pesquisa. De todo modo, é possível trabalhar com uma moda mais ética, com maior valorização das pessoas, do meio ambiente e da sociedade, e ainda sim, possuir retorno financeiro, já que o custo de produção esteve dentro da média de mercado. Mas é primordial ter planejamento e, sobretudo, um escopo bem definido, isto é, conhecer o consumidor, o mercado e estar atento às possibilidades e vazios a serem preenchidos. 


\section{REFERÊNCIAS}

ANICET, Anne; BESSA, Pedro; BROEGA, Ana Cristina. Ações na área da moda em busca de um design sustentável. In: COLÓQUIO DE MODA, 7., 2011, Maringá. Anais [...]. Maringá, 2011. Disponível em: http:// repositorium.sdum.uminho.pt/bitstream/1822/14959/1/GT89897\%20 A\%c3\%a7\%c3\%b5es\%20na\%20\%c3\%a1rea\%20da\%20moda\%20em\%20 busca\%20de\%20um\%20design\%20sustent\%c3\%a1vel.pdf. Acesso em: 25 nov. 2016.

BAUMAN, Zygmunt. Modernidade líquida. Rio de Janeiro: Jorge Zahar, 2001.

CALÍOPE, Thalita Silva. Moda e sustentabilidade: uma relação contraditória? Um ensaio sob a perspectiva do ciclo de vida. In: ENCONTRO INTERNACIONAL SOBRE GESTÃO EMPRESARIAL E MEIO AMBIENTE, 17., 2015, São Paulo. Anais [...]. São Paulo, 2015. Disponível em: http://engemausp. submissao.com.br/17/anais/arquivos/347.pdf. Acesso em: 25 nov. 2016.

CHIAPETTA, Marina Santos. Elegância consciente: a moda em seus diversos estilos sustentáveis. Disponível em: http://www.ecycle.com.br/component/ content/article/73-vestuario/3481-que-moda-etica-slow-fashion-ecologicaverde-sustentavel-alternativa-upcycle-upcycling-eco-cycle-chic-veganaestilo-vida-organico-consumo-consciente-sustentabilidade-saude-impactomeio-ambiente-natureza-vestir-bem-produto-roupas-materiais.html. Acesso em: 25 nov. 2016.

FASHION REVOLUTION. Disponível em: http://fashionrevolution.org/about/ why-do-we-need-a-fashion-revolution/. Acesso em: 17 set. 2017.

FERRONATO, Priscila Boff; FRANZATO, Carlo. Open design e slow fashion para a sustentabilidade do sistema de moda. ModaPalavra, Florianópolis, v. 9, p. 104-115, out. 2015. Disponível em: http://www.revistas.udesc.br/index.php/ modapalavra/article/view/7256. Acesso em: 14 nov. 2016.

FLETCHER, Kate. Fashion and Sustainability FAQs. 2012. Disponível em: http:// katefletcher.com/fashion-and-sustainability-faqs/. Acesso em: 25 nov. 2016.

FLETCHER, Kate. Slow fashion. 2007. Disponível em: http://www.theecologist. org/green_gree_iving/clothing/269245/slow_fashion.html. Acesso em: 25 nov. 2016.

GIL, Antonio Carlos. Como elaborar projetos de pesquisa. 5. ed. São Paulo: Atlas, 2010. 
GONCALVES, Marco Antonio. Indivíduo hipermoderno e consumo. In: SEMINÁRIO DE PÓS-GRADUAÇÃO EM FILOSOFIA DA UFSCAR, 7., 2011, São Carlos. Anais [...]. São Carlos, 2011. Disponível em: http://www.ufscar. $\mathrm{br}$ / semppgfil/wp-content/uploads/2012/05/marcogoncalves.pdf. Acesso em: 25 nov. 2016.

GWILT, Alison. Moda sustentável: um guia prático. São Paulo: Gustavo Gili, 2014.

KARKOTLI, Gilson. Responsabilidade social empresarial. 2. ed. Petrópolis: Vozes, 2007.

LEE, Matilda. Eco chic: o guia de moda ética para a consumidora consciente. São Paulo: Larousse do Brasil, 2009.

LIPOVESTKY, Gilles. Entrevista: Gilles Lipovetsky aborda o papel do consumo na atualidade. Globo Universidade, São Paulo, 2012. Disponível em: http:// redeglobo.globo.com/globouniversidade/noticia/2012/10/entrevista-gilleslipovetsky-aborda-o-papel-do-consumo-na-atualidade.html. Acesso em: 28 jul. 2017.

LIPOVETSKY, Gilles. O império do efêmero: a moda e seu destino nas sociedades modernas. São Paulo: Companhia das Letras, 1991.

LIPOVETSKY, Gilles. Os tempos hipermodernos. São Paulo: Barcarolla, 2004.

LÖBACH, Bernd. Design industrial: bases para a configuração dos produtos industriais. São Paulo: Blucher, 2001.

NISHIMURA, Maicon Douglas Livramento; GONTIJO; Leila Amaral. Slow fashion e o produto de moda com enfoque no usuário. In: CONGRESSO BRASILEIRO DE PESQUISA E DESENVOLVIMENTO EM DESIGN, 12., 2016, Belo Horizonte. Anais [...] Belo Horizonte, 2016. Disponível em: http://www. proceedings.blucher.com.br/article-details/slow-fashion-e-o-produto-demoda-com-enfoque-no-usurio-24648. Acesso em: 25 nov. 2016.

NISHIMURA, Maicon Douglas Livramento; GONTIJO; Leila Amaral. Vestuário sustentável. Pensamento \& Realidade, São Paulo, v. 32, n. 2, p. 110-122, set. 2017. Disponível em: https://revistas.pucsp.br/index.php/ pensamentorealidade/article/view/31818. Acesso em: 17 set. 2017.

SALCEDO, Elena. Moda ética para um futuro sustentável. São Paulo: Gustavo Gili, 2014. 
SCHULTE, Neide Köhler. Contribuições da ética ambiental biocêntrica e do veganismo para o design do vestuário sustentável. 2011. Tese (Doutorado em Artes e Design) - Pontifícia Universidade Católica do Rio de Janeiro, Rio de Janeiro, 2011. Disponível em: http://www.maxwell.vrac.puc-rio.br/ acessoConteudo.php?nrseqoco=65199. Acesso em: 25 nov. 2016.

SCHULTE, Neide Köhler; LOPES, Luciana Dornbush. Sustentabilidade ambiental no produto de moda. In: ENCONTRO DE SUSTENTABILIDADE EM PROJETO DO VALE DO ITAJAÍ, 2007, Itajaí. Anais [...]. Itajaí, 2007. Disponível em: http://ensus2007.paginas.ufsc.br/files/2015/08/SustentabilidadeAmbiental-no-Produto-de-Moda1.pdf. Acesso em: 25 nov. 2016.

TREPTOW, Doris. Inventando moda: planejamento de coleção. Brusque: D. Treptow, 2007. 